\title{
Anxiety Symptoms During Adolescence Predicts Salivary Cortisol in Early Adulthood Among Blacks; Sex differences
}

\author{
Shervin Assari, ${ }^{1,2, *}$ Maryam Moghani Lankarani, ${ }^{1,3}$ Cleopatra Howard Caldwell, ${ }^{2,4}$ and Marc \\ Zimmerman $^{4}$ \\ ${ }^{1}$ Department of Psychiatry, School of Medicine, University of Michigan, Ann Arbor, USA \\ ${ }^{2}$ Center for Research on Ethnicity Culture and Health, School of Public Health, University of Michigan, Ann Arbor, USA \\ ${ }^{3}$ Medicine and Health Promotion Institute, Tehran, IR Iran \\ 4 Department of Health Behavior and Health Education, School of Public Health, University of Michigan, Ann Arbor, USA \\ ${ }^{*}$ Corresponding author: Shervin Assari, Department of Psychiatry, School of Medicine, University of Michigan, Ann Arbor, USA. Tel: +1-7342320445, Fax: +1-7346158739, \\ E-mail: assari@umich.edu
}

Received 2014 February 5; Revised 2015 September 14; Accepted 2015 September 27.

\begin{abstract}
Background:Although the linkbetween psychological distress and altered cortisol level has been already shown; very limited information exists about this association among Black youth.

Objectives: We tested sex differences in predictive role of symptoms of anxiety during adolescence on annual decline in morning salivary cortisol levels in early adulthood among Black youth.

Patients and Methods: Data came from wave 1 (year 1994), wave 6 (year 2000), and wave 7 (year 2001) of the Flint adolescent study. In this study 176 Black youth ( 85 males and 91 females) were followed for 7 years from mean age of 15 at baseline to 22 at the end of follow up. Linear regression was used for data analysis with change in salivary cortisol from 2000 to 2001 as the dependent variable, symptoms of anxiety, at 1994 as independent variable, age, number of employed parents, depressive symptoms and alcohol use at 1994 as controls, and sex as the moderator.

Results: Higher level of anxiety symptoms at 1994 was predictive of a higher decline in morning salivary cortisol from 2000 to 2001 for all youths, while the effects of baseline socio-economics, depressive symptoms, and alcohol use were controlled. Among female participants, anxiety symptoms at 1994 were predictive of a greater decline in morning salivary cortisol level from 2000 to 2001. The association was not found among males.

Conclusions: Our findings suggest sex differences in the predictive role of anxiety symptoms during adolescence on the annual decline in cortisol level during early adulthood. While most research on this topic is among White middle class individuals, our findings shed more light on the longitudinal links between psychological distress and the hypothalamus-pituitary-adrenal (HPA) axis function among Black youth.
\end{abstract}

Keywords: African Americans, Anxiety, Young Adult, Hydrocortisone/Blood, MH-Hypothalamo-Hypophyseal System, Physiopathology, Male, Female

\section{Background}

The hypothalamus-pituitary-adrenal (HPA) axis is responsible for maintenance of hemostasis. Following exposure to stress, secretion of corticotropin-releasing hormone $(\mathrm{CRH})$ by hypothalamus stimulates secretion of adrenocorticotrophic hormone (ACTH) by the pituitary gland. Subsequently, release of ACTH results in the release of cortisol from the adrenal glands (1). Cortisol is involved in response to stress (2) and several other important physiological processes such as growth, reproduction (3-5), and energy balance (6).

Altered HPA function seems to be one of the intermediate mechanisms by which psychosocial disadvantage such as long term exposure to high levels of chronic stress increase risk of adverse health outcomes (7-9). In this view, long term exposure to stress over the life course may result in non-reversible modifications to the HPA system with the end product of cortisol, that although is designed to save the individual in response to acute stress, its chronic activation will be damaging for the organism $(7,10-12)$. This is supported by a large body of research evidence from studies on humans, primates, and rodents that suggest that exposure to stress during critical developmental periods have permanent effects on HPA regulation, with deleterious effects on health (13). The psychological distress-HPA dysfunction link has been suggested by a considerable amount of research. $(3,14-16)$ Yet, most of the available knowledge on this link originates from cross sectional studies or longitu-

Copyright (C) 2015, Research Institute For Endocrine Sciences and Iran Endocrine Society. This is an open-access article distributed under the terms of the Creative Commons Attribution-NonCommercial 4.0 International License (http://creativecommons.org/licenses/by-nc/4.0/) which permits copy and redistribute the material just in noncommercial usages, provided the original work is properly cited. 
Assari S et al.

dinal studies with short term follow up of mostly White middle class adults $(17,18)$. Less is known about long term association between anxiety symptoms and HPA axis activity among Black youth (19). Although research has confirmed a link between psychosocial stress, anxiety disorders, and dysregulation in HPA function (20, 21), the research on the association between anxiety during adolescence and HPA axis activity in adulthood is scarce (19). There is considerable evidence for HPA axis dysregulation in posttraumatic stress disorder (PTSD) (21, 22), separation anxiety (1), panic disorder, with agoraphobia, and those with comorbid depression (19), and pharmacological agents that increase anxiety in both normal people and patients with panic disorder raise the stress hormone levels (23). Different anxiety disorders (e.g. generalized anxiety disorder, panic disorder, and PTSD) affect stress hormones in distinct ways. While anticipatory anxiety and generalized anxiety disorder activate both the HPA and the sympatho-adrenal axes, panic attack has been shown to cause major sympathetic activation, with very little effect on the HPA axis (23).

\section{Objectives}

As the literature has suggested that the links between acute and chronic stress, psychopathology, and HPA function may differ among males and females (24-31), in the current study we examined sex differences in the predictive role of anxiety symptoms during adolescence on annual decline of morning salivary cortisol level during early adulthood among Blacks. As most of the research on the association between HPA axis and anxiety originates from cross-sectional studies $(1,19)$, the current longitudinal study with long term follow up is believed to make a unique contribution to the literature.

\section{Patients and Methods}

\subsection{Design and Setting}

Data came from the Flint adolescent study (FAS), a longitudinal study conducted from 1994 to 2012 in Flint, Michigan. The study protocol was approved by the University of Michigan Institutional Review Board and all participants signed consent or assent forms before each interview $(24,32)$.

\subsection{Original Study}

The Flint adolescent study (FAS), is a longitudinal study with 12 waves of data collection. The FAS followed 850 Black/African American and White adolescents from their $9^{\text {th }}$ grade to their transition into young adulthood. Data for the current study came from wave 1 (1994), wave 6 (2000), and wave 7 (2001) of the study. Retention rates were $90 \%$ from waves 1 to 4 and $75 \%$ from waves 4 to 8 (33-35).

\subsection{Participants and Sampling}

Participants were sampled from four local public high schools. The study enrolled students in the fall semester of ninth grade if they had a grade point average (GPA) of 3.0 or lower in $8^{\text {th }}$ grade and they did not have a diagnosis of developmental disability or emotional impairment. The current analysis only included Black/African Americans who provided saliva samples in waves 6 and 7, and had stayed in the study until wave 9. Youth who consented to saliva sampling were not different from the overall wave 6 sample. The decision of not to include Whites was made because of very few Whites individuals included in waves 6 and 7 .

\subsection{Procedure}

Data were collected during structured face-to-face interviews conducted either at school or at alternative community locations. A self-administered questionnaire assessed more sensitive information and was distributed at the conclusion of each interview to facilitate confidentiality. This study followed students, irrespective of drop out from schools. On average, each interview lasted 50 - 60 minutes.

\subsection{Measures}

Salivary cortisol level: Saliva samples were collected from a subset of samples $(\mathrm{N}=201)$. This number was a proportion of all participants who were present in wave $6(\mathrm{~N}=573)$, provided consent to the procedure, and were eligible for the saliva collection. Eligibility for saliva collection included not being pregnant, and not having eaten, drank or used tobacco in the hour prior to the collection. Participants provided saliva samples at the beginning of the interview, which happened before 11.00 A.M. in all cases. Samples were placed on ice prior to transportation and assay. Cortisol was specifically assessed by high sensitivity salivary cortisol enzyme immunoassay by Salimetrics, Incorporated. The saliva samples were thawed and centrifuged at 1,500 rpm for 15 minutes before assay. The assay follows standard enzyme immunoassay procedures as previously described $(24,33)$. The intra- and inter-assay coefficient of variations ranged from 3.88 to $7.12 \%$ and 6.69 to 6.88 $\%$, respectively. The lower limit of sensitivity of this assay is $0.007 \mu \mathrm{g} / \mathrm{dL}$ (25).

Symptoms of anxiety (independent variable): Symptoms of anxiety were measured by the brief symptom inventory (26). Six items assess the frequency of feeling uncomfortable due to symptoms of anxiety during the past week. Response options are on a Likert scale that ranged from 1 (not at all uncomfortable) to 5 (extremely uncomfortable). Items were averaged to form a scale. This scale has been shown to have high internal consistency and test-retest reliability $(27,28)$. The Cronbach's alpha is 78 for the Black youth at wave 1 in the present study (Appendices).

Covariates: Age, family socioeconomic status (parental 
Assari S et al.

employment), symptoms of depression, and alcohol use were used as control variables.

Symptoms of depression: Depressive symptoms were measured by six items from the brief symptom inventory (26). These items assess the frequency of feeling uncomfortable during the past seven days due to symptoms of depression such as feeling hopeless about the future, and having no interest in things. Response options on the Likert scale ranged from 1 (not at all uncomfortable) to 5 (extremely uncomfortable). These six items were averaged to form the final scale. Researchers have found that this scale has high internal consistency and test-retest reliability and is valid to use with adolescents $(27,28)$. Cronbach's alpha was 79 for the current sample at wave 1 (Appendices).

Alcohol use: Participants were asked to report if they had ever used alcohol in their lifetime. If alcohol was reported, frequency of alcohol use in the past 30 days ( $0=$ never, $1=$ once a month or less, $2=2-3$ times a month, 3 = about once a week, $4=2-6$ times a week, $5=$ about once a day, $6=$ more than once a day) was then assessed. Participants who had never used alcohol were coded as never in the past 30 days. Because of relatively low rates of marijuana use (skew), the variable was recoded into four categories for analysis $(0=$ never, $1=3$ or fewer times a month, 2 = 1 - 6 times a week, 3 = daily use) (Appendices).

\subsection{Data Analysis}

We used SPSS 20.0 (PASW, Chicago, Il) for data analysis. Means and standard deviations (SD) were reported for baseline age, anxiety symptoms, depressive symptoms, alcohol use, and cortisol levels at waves 6 and 7. Pearson's correlation test was used to investigate unadjusted bivariate associations between the study variables. We used paired t-test to compare mean cortisol levels at 2000 and 2001. For multivariable analysis, first we ran a logistic regression to the pooled sample. Then we ran logistic regression models specific to each sex. Level of anxiety symptoms was the independent variable of interest, age, number of employed parents, depression, and alcohol use at baseline were control variables, and sex was the moderator. P Values less than 0.05 were considered significant.

\section{Results}

Age of the participants ranged from 14 to 17 years, with a mean of 15 and a standard deviation of 1 year, respectively. From the total 176 participants, 85 were male (48.3\%), and 91 were female (51.7\%). Mean cortisol level showed a decline from 2000 to 2001 (Table 1).

As Table 2 shows, in the pooled sample, age was correlated with depressive symptoms and alcohol use, but not anxiety symptoms. Cortisol at 2001 was lower among females; however, cortisol and sex were not associated at 2000. Cortisol at 2000 was also not correlated with age, symptoms of anxiety, symptoms of depression, or alcohol use at 1994. Symptoms of anxiety, depression and alcohol use were all positively correlated at baseline (Table 2).

As Table 3 shows, age was positively correlated with anxiety and depressive symptoms among males but not females. Age was positively correlated with alcohol use among males but not females. Number of parents working was negatively associated with depressive symptoms among males, and was positively associated with anxiety and depressive symptoms among females. Cortisol was not correlated with age, anxiety, depression, or alcohol use at baseline among males or females (Table 3 ).

Results of the regressions are presented in Table 4. As this table shows, sex and anxiety were the only variables that were correlated with change in cortisol over time in the pooled sample. Age, employed parent, depressive symptoms, and alcohol use were not correlated with change in cortisol over time in the pool sample.

Among males, alcohol use, and among females, symptoms of anxiety were associated with change in cortisol over time. Age, symptoms of anxiety, employed parent, and depressive symptoms among males and age, employed parent, depressive symptoms, and alcohol use among females were not associated with change of cortisol over time (Table 4 ).

\begin{tabular}{lcccccc}
\hline \multirow{2}{*}{ Table 1. Descriptive Statistics of Socio-Economics, Mental Health, and Cortisol Among Blacks Based on Sex } \\
\hline & \multicolumn{2}{c}{ All } & \multicolumn{2}{c}{ Males } & \multicolumn{2}{c}{ Females } \\
\cline { 2 - 7 } Variables & Min - Max & Mean \pm SD & Min - Max & Mean \pm SD & Min - Max & Mean \pm SD \\
\hline Age, $\mathbf{y}$ & $13.87-16.88$ & $14.86 \pm 0.65$ & $13.87-16.85$ & $14.94 \pm 0.66$ & $13.89-16.88$ & $14.79 \pm 0.62$ \\
$\begin{array}{l}\text { Number of working } \\
\text { parents }\end{array}$ & $0.00-2.00$ & $1.42 \pm 0.69$ & $0.00-2.00$ & $1.46 \pm 0.66$ & $0.00-2.00$ & $1.38 \pm 0.71$ \\
Anxiety symptoms & $1.00-4.67$ & $1.6 \pm 0.64$ & $1.00-4.00$ & $1.47 \pm 0.52$ & $1.00-4.67$ & $1.71 \pm 0.71$ \\
Depressive Symptoms & $1.00-4.83$ & $1.66 \pm 0.71$ & $1.00-3.67$ & $1.48 \pm 0.53$ & $1.00-4.83$ & $1.82 \pm 0.81$ \\
Alcohol Use & $1.00-21.00$ & $4.9 \pm 4.65$ & $1.00-21.00$ & $4.6 \pm 4.62$ & $1.00-21.00$ & $5.18 \pm 4.66$ \\
$\begin{array}{l}\text { Morning cortisol level } \\
\text { (pg/mL), at year 2000 }\end{array}$ & $0.001-1.15$ & $0.24 \pm 0.19$ & $0.01-1.15$ & $0.26 \pm 0.18$ & $0.03-1.03$ & $0.23 \pm 0.19$ \\
$\begin{array}{l}\text { Morning cortisol level } \\
\text { (pg/mL), at year 2001 }\end{array}$ & $0.01-1.31$ & $0.22 \pm 0.23$ & $0.02-1.31$ & $0.27 \pm 0.26$ & $0.01-1.14$ & $0.17 \pm 0.18$ \\
\hline a & & & & &
\end{tabular}

\footnotetext{
${ }^{\mathrm{a}}$ Statistics obtained in the year 1994.
} 
Assari S et al.

\begin{tabular}{|c|c|c|c|c|c|c|c|c|}
\hline & $\mathbf{1}$ & 2 & 3 & 4 & 5 & 6 & 7 & 8 \\
\hline 1- Age & 1 & $-0.120^{\mathrm{a}}$ & $-0.140^{\mathrm{a}}$ & -0.005 & 0.015 & 0.038 & $0.086^{\mathrm{b}}$ & $0.106^{a}$ \\
\hline 2-Sex (female) & & 1 & -0.06 & -0.061 & $-0.222^{\mathrm{a}}$ & $0.193^{\mathrm{a}}$ & $0.240^{\mathrm{a}}$ & 0.062 \\
\hline 3- Number of working Parents & & & 1 & 0.055 & -0.004 & -0.02 & -0.036 & 0.017 \\
\hline 4- Cortisol pre, pg/mL & & & & 1 & 0.112 & -0.049 & -0.068 & -0.023 \\
\hline 5- Cortisol post, pg/mL & & & & & 1 & $-0.153^{\mathrm{a}}$ & $-0.145^{\mathrm{a}}$ & 0.01 \\
\hline 6-Anxiety symptoms 1 & & & & & & 1 & $0.731^{\mathrm{a}}$ & $0.213^{\mathrm{a}}$ \\
\hline 7- Depressive symptoms 1 & & & & & & & 1 & $0.254^{\mathrm{a}}$ \\
\hline 8-Alcohol use 1 & & & & & & & & 1 \\
\hline
\end{tabular}

$\mathrm{a}_{\mathrm{p}}<0.01$

$\mathrm{b}_{\mathrm{p}}<0.05$

\begin{tabular}{|c|c|c|c|c|c|c|c|}
\hline & $\mathbf{1}$ & 2 & 3 & 4 & 5 & 6 & 7 \\
\hline 1- Age & 1 & $-0.132^{b}$ & 0.009 & -0.013 & -0.045 & 0.073 & $0.129^{b}$ \\
\hline 2- Number of working parents & $-0.162^{c}$ & 1 & 0.074 & -0.013 & -0.109 & $-0.176^{c}$ & -0.044 \\
\hline 3- Cortisol pre (pg/mL), at year 2000 & -0.029 & 0.034 & 1 & 0.057 & -0.068 & 0.002 & -0.025 \\
\hline 4- Cortisol post (pg/mL), at year 2001 & -0.019 & 0.021 & 0.156 & 1 & -0.106 & -0.085 & 0.107 \\
\hline 5-Anxiety symptoms 1 & $0.146^{c}$ & 0.060 & -0.024 & -0.140 & 1 & $0.626^{c}$ & $0.150^{c}$ \\
\hline 6- Depressive symptoms 1 & $0.157^{c}$ & 0.070 & -0.093 & -0.127 & $0.763^{c}$ & 1 & $0.198^{c}$ \\
\hline 7-Alcohol use at 1994 & 0.100 & 0.078 & -0.017 & -0.082 & $0.250^{\mathrm{C}}$ & $0.285^{c}$ & 1 \\
\hline
\end{tabular}

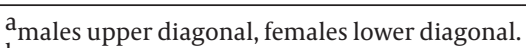

$\mathrm{b}_{\mathrm{p}<0.05}$

$\mathrm{c}_{\mathrm{p}}<0.01$.

Table 4 Summary of Regressions with Cortisol at Year 2001 as Outcome Among Blacks Based on Sex ${ }^{\mathrm{a}}$

\begin{tabular}{|c|c|c|c|c|c|c|c|c|c|}
\hline & & All & & & Males & & & emales & \\
\hline & B (SE) & 95\% CI for B & $\mathbf{P}$ & B (SE) & $\mathbf{9 5} \%$ CI for B & $\mathbf{P}$ & B (SE) & $\mathbf{9 5} \%$ CI for B & $\mathbf{P}$ \\
\hline Sex (female) & $-0.206(0.036)$ & $-0.162-0.02$ & 0.012 & - & - & - & - & - & - \\
\hline Age & $0.005(0.026)$ & $-0.051-0.054$ & 0.951 & $-0.061(0.043)$ & $-0.107-0.063$ & 0.602 & $0.036(0.031)$ & $-0.052-0.071$ & 0.759 \\
\hline $\begin{array}{l}\text { Employed } \\
\text { parent at year } \\
1994\end{array}$ & $0.033(0.026)$ & $\begin{array}{l}-0.040- \\
0.062\end{array}$ & 0.682 & $0.020(0.043)$ & $-0.078-0.093$ & 0.863 & $0.005(0.030)$ & $-0.058-0.061$ & 0.969 \\
\hline $\begin{array}{l}\text { Depressive } \\
\text { symptoms at } \\
\text { year } 1994\end{array}$ & $0.036(0.035)$ & $-0.058-0.08$ & 0.758 & $-0.016(0.062)$ & $-0.130-0.117$ & 0.915 & $0.157(0.037)$ & $-0.042-0.107$ & 0.388 \\
\hline $\begin{array}{l}\text { Alcohol use at } \\
\text { year } 1994\end{array}$ & $0.101(0.004)$ & $-0.003-0.014$ & 0.212 & $0.289(0.007)$ & $0.003-0.032$ & 0.019 & $-0.130(0.005)$ & $-0.015-0.004$ & 0.269 \\
\hline $\begin{array}{l}\text { Anxiety symp- } \\
\text { toms at year } \\
1994\end{array}$ & $-0.243(0.044)$ & $-0.179-0.004$ & 0.04 & $-0.238(0.087)$ & $-0.310-0.038$ & 0.124 & $-0.350(0.045)$ & $-0.176-0.000$ & 0.050 \\
\hline $\begin{array}{l}\text { Cortisol, pg/mL } \\
\text { at year } 2000\end{array}$ & $0.085(0.091)$ & $-0.081-0.277$ & 0.282 & $0.076(0.170)$ & $-0.228-0.449$ & 0.517 & $0.144(0.093)$ & $-0.069-0.304$ & 0.215 \\
\hline
\end{tabular}




\section{Discussion}

High level of anxiety symptoms among female Black adolescents at $\mathbf{2 0 0 0}$ was predictive of a higher annual decline in cortisol level 7 years later when they are early adults. Among males, the baseline alcohol use but not level of anxiety symptoms was predictive of later annual decline in cortisol level.

In line with our findings, several $(1,2,19,29)$ if not all (30) studies have shown an association between level of anxiety and cortisol levels in individuals with chronic conditions, healthy adults, and psychiatric disorders. In a study among patients with a chronic medical condition, the correlation coefficient between anxiety symptoms and salivary cortisol was 0.980 (P Value $<0.001$ ) suggesting an extremely strong positive correlation between the two variables (31). In support of our findings, sex differences in the HPA function in response to acute and chronic stress have also been reported previously (36-43).

In line with our study, drinking alcohol has also shown to be linked to the function of HPA axis and cortisol level (44). Animal studies $(45,46)$ and epidemiological studies $(17,47-50)$ have documented an effect of alcohol use on HPA axis activity. Epidemiological studies among apparently healthy population have found elevated cortisol levels in heavy drinkers $(51,52)$ and alcohol-dependent individuals show altered HPA axis function while in withdrawal (44). The slope of cortisol decline over the day may be reduced in heavy drinkers (44). Some research also supports our finding on sex differences in the drinking-cortisol level link (44). For instance, Badrick and colleagues found a positive association between units of alcohol intake per week and cortisol among men but not women. In women the cortisol awakening response was greater in heavy drinkers compared with moderate drinkers (44).

This study makes a unique contribution to the literature by extending the current knowledge on the longitudinal link between anxiety and HPA axis among Black youth who experience poverty, blocked opportunities, high risk environment, and unemployment. Most previous research has enrolled a sample which is mostly White middle class (53).

Our findings suggest that for Blacks who live in disadvantaged urban areas, high anxiety symptoms during adolescence is predictive of later annual decline in cortisol level over early adulthood, especially among females. Findings can be explained by the concept of 'allostatic over-load' which suggests that long term exposure to chronic, excessive stress causes in poor regulated stress response that predicts a wide range of poor health outcomes (10-12).

Our findings on the link between anxiety symptoms and cortisol level can be better understood with the more controlled studies such as one by Abelson and colleagues (2) who documented elevated overnight cortisol levels among patients with panic disorder. Authors studied pa- tients with panic disorder for a) activity of HPA axis at rest over a full circadian cycle, b) activation of HPA axis by a panicogenic respiratory stimulant that does not directly stimulate the HPA axis, and c) activation of HPA axis after a panicogenic that does directly stimulate the HPA axis and showed exaggerated paradigm-related ACTH secretion in patients with panic disorder. Authors concluded that the HPA axis dysregulation associated with panic disorder may be due to hypersensitivity to contextual cues (2).

Our findings are also consistent with a study that examined adrenocortical activity among normally developing and at-risk youth with internalizing symptoms (54). The researchers found a link between internalizing problems and gradual or steep declines in basal cortisol production. Internalizing symptoms were associated with immediate and delayed cortisol reactivity to social performance stressors. Authors found no evidence of an association between externalizing problems and cortisol level, however. In that study, the symptoms ranged from subclinical to clinical levels of psychopathology and salivary cortisol levels were measured to assess basal, diurnal variation, and responses to social stressors (54).

Our findings on sex differences are also supported by previous research. Kallen et al. (1) explored sex differences in the link between the level of anxiety with basal HPA axis activity in youth with anxiety disorders. Among 8 - 16 year olds, they found that in girls but not boys, high level of anxiety was associated with a weaker rise in early morning cortisol concentrations. In their study, however, among both males and females, separation anxiety was associated with basal cortisol levels. In that study, separation anxiety and physical anxiety symptoms predicted cortisol concentrations at noon (1).

Current study focused on anxiety symptoms and did not measure anxiety disorders or the sub-type of anxiety disorder. Subtype of anxiety disorder modifies the effect of anxiety on HPA function (1). For instance, change in HPA axis is shown among patients with panic disorder with agoraphobia and anxious patients with comorbid depressive disorder (19).

Researchers have also reported results that do not support our findings. Ockenfels et al. (55) did not find an association between chronic stress and overall cortisol excretion or cortisol reactivity. In their study, however, self-reported chronic stress was linked to the diurnal pattern of cortisol excretion. Higher morning and lower evening levels of cortisol were seen among individuals who reported high level of chronic stress (55). The sample for that study, however, was mostly composed of Whites and the study was cross-sectional in design.

Our findings have implications for understanding and elimination of health disparities among Black youth. Blacks including Black youth are exposed to disproportionally higher levels of chronic stressors and report higher levels of psychological distress, even if they less 
frequently meet criteria for anxiety and other anxiety disorders $(56,57)$. Among Blacks, disturbance of the HPA axis may be at least partially responsible for higher levels of hypertension and cardiovascular diseases (58), obesity (59), metabolic disorders (60), diabetes (61) and even cardiovascular risk (62). The results are also important because they link to important concepts of anxiety (6368 ) and cortisol (69) in the general population among a minority group. Sex differences found in this study are another emphasis on specificity of risk rather than its universality (70).

Our study has a few limitations. The study did not enroll a national or a representative sample, as it enrolled samples from a single city in Midwest. Measurement of cortisol was also limited in the current study. We used annual decline in average morning concentration of cortisol, however, the HPA function can be better measures using the stress response test and area under the curve of cortisol and ACTH secretion (71). In addition, the sample size was not very large. Finally, the current study measured anxiety symptoms, not anxiety disorder. This is very important as type of anxiety disorder influences the HPA axis function. For instance, some evidence has shown hyper-suppression in PTSD, which is very different from panic disorder or physical and general anxiety disorder $(2,19,22)$.

To conclude, our findings suggest that among female Black youth, anxiety symptoms during adolescence predict subsequent annual change in morning cortisol level during early adulthood. The findings help us better understand the longitudinal connection between of symptoms of anxiety during adolescence and rate of the cortisol decline in early adulthood. Our findings suggest that among female but not male Black youth, level of anxiety symptoms during adolescence may have some implications for prediction of trajectory of the HPA axis function several years later. Future research is needed to better understand the complex links between race, sex, chronic stress, psychological symptoms, psychopathology, alteration of HPA function, and health disparities.

\section{Footnotes}

Authors' Contributions:The original idea of this analysis was developed by Shervin Assari, who has also analyzed the data and drafted the manuscript. The design and conduction of the original study and supervision of data collection was done by Marc Zimmerman. Marc Zimmerman and Cleopatra Caldwell have also contributed to the content of this manuscript. All authors have read and approved final draft of the manuscript.

Funding/Support:This study was funded by the National Institute on Drug Abuse (NIDA) (grant DA07484). The content of this article does not necessarily reflect the views or policies of the National Institute on Drug Abuse. Shervin Assari is supported by the Heinz C. Prechter Bipolar Research Fund and the Richard Tam Foundation at the University of Michigan Depression Center.

\section{Appendices}

Please visit article's online version for appendices.

\section{References}

1. Kallen VL, Tulen JH, Utens EM, Treffers PD, De Jong FH, Ferdinand RF. Associations between HPA axis functioning and level of anxiety in children and adolescents with an anxiety disorder. Depress Anxiety. 2008;25(2):131-41. doi: 10.1002/da.20287. [PubMed: 17340603]

2. Abelson JL, Khan S, Liberzon I, Young EA. HPA axis activity in patients with panic disorder: review and synthesis of four studies. Depress Anxiety. 2007;24(1):66-76. doi: 10.1002/da.20220. [PubMed: 16845643]

3. Chrousos GP. Stressors, stress, and neuroendocrine integration of the adaptive response. The 1997 Hans Selye Memorial Lecture Ann N Y Acad Sci. 1998;851:311-35. [PubMed: 9668623]

4. de Kloet ER. Hormones, brain and stress. Endocr Regul. 2003;37(2):51-68. [PubMed: 12932191]

5. Sapolsky RM, Romero LM, Munck AU. How do glucocorticoid influence stress responses? Integrating permissive, suppressive, stimulatory, and preparative actions. Endocr Rev. 2000;21(1):5589. doi: 10.1210/edrv.21.1.0389. [PubMed:10696570]

6. Brillon DJ, Zheng B, Campbell RG, Matthews DE. Effect of cortiso on energy expenditure and amino acid metabolism in humans. Am J Physiol. 1995;268(3 Pt 1):E501-13. [PubMed: 7900796]

7. McEwen BS, Seeman T. Protective and damaging effects of mediators of stress. Elaborating and testing the concepts of allostasis and allostatic load. Ann N Y Acad Sci. 1999;896:30-47. [PubMed: 10681886]

8. McEwen BS. Brain on stress: how the social environment gets under the skin. Proc Natl Acad Sci U S A. 2012;109 Suppl 2:17180-5. doi 10.1073/pnas.1121254109. [PubMed: 23045648]

9. Javanbakht A, King AP, Evans GW, Swain JE, Angstadt M, Phan KL, et al. Childhood Poverty Predicts Adult Amygdala and Frontal Activity and Connectivity in Response to Emotional Faces. Front Behav Neurosci. 2015;9:154. doi:10.3389/fnbeh.2015.00154. [PubMed: 26124712]

10. McEwen BS. Stress, adaptation, and disease. Allostasis and allostatic load. Ann N Y Acad Sci.1998;840:33-44. [PubMed: 9629234]

11. Seeman TE, Singer BH, Rowe JW, Horwitz RI, McEwen BS. Price of adaptation-allostatic load and its health consequences. MacArthur studies of successful aging. Arch Intern Med. 1997;157(19):2259-68. [PubMed: 9343003]

12. McEwen BS. Allostasis and allostatic load: implications for neuropsychopharmacology. Neuropsychopharmacology. 2000;22(2):108-24. doi: 10.1016/s0893-133x(99)00129-3. [PubMed: 10649824]

13. Flinn MV. Are cortisol profiles a stable trait during child development? Am J Hum Biol. 2009;21(6):769-71. doi: 10.1002/ajhb.20981. [PubMed: 19693958]

14. Levine S. Influence of psychological variables on the activity of the hypothalamic-pituitary-adrenal axis. Eur J Pharmacol. 2000;405(1-3):149-60. [PubMed:11033322]

15. Kirschbaum C, Hellhammer DH. Salivary cortisol in psychoneuroendocrine research: recent developments and applications Psychoneuroendocrinology. 1994;19(4):313-33. [PubMed: 8047637]

16. Pruessner M, Hellhammer DH, Pruessner JC, Lupien SJ. Self-reported depressive symptoms and stress levels in healthy young men: associations with the cortisol response to awakening. Psychosom Med. 2003;65(1):92-9. [PubMed:12554820]

17. Nemeroff CB, Vale WW. The neurobiology of depression: inroads to treatment and new drug discovery. J Clin Psychiatry. 2005;66 Suppl 7:5-13. [PubMed:16124836]

18. Young EA, Lopez JF, Murphy-Weinberg V, Watson SJ, Akil H. Mineralocorticoid receptor function in major depression. Arch Gen Psychiatry. 2003;60(1):24-8. [PubMed: 12511169]

19. Vreeburg SA, Zitman FG, van Pelt J, Derijk RH, Verhagen JC, van Dyck R, et al. Salivary cortisol levels in persons with and without different anxiety disorders. Psychosom Med. 2010;72(4):340-7. doi:10.1097/PSY.ob013e3181d2foc8. [PubMed: 20190128] 
Assari S et al.

20. Roy-Byrne PP, Geraci M, Uhde TW. Life events and the onset of panic disorder. Am J Psychiatry. 1986;143(11):1424-7. [PubMed: 3777233]

21. de Kloet ER, Joels M, Holsboer F. Stress and the brain: from adaptation to disease. Nat Rev Neurosci. 2005;6(6):463-75. doi:10.1038/ nrn1683. [PubMed:15891777]

22. Yehuda R, Southwick SM, Krystal JH, Bremner D, Charney DS, Mason JW. Enhanced suppression of cortisol following dexamethasone administration in posttraumatic stress disorder. Am J Psychiatry. 1993;150(1):83-6. [PubMed: 8417586]

23. Graeff FG. [Anxiety, panic and the hypothalamic-pituitary-adrenal axis]. Rev Bras Psiquiatr. 2007;29 Suppl 1:S3-6. [PubMed 17546345]

24. Assari S, Caldwell CH, Zimmerman MA. Sex differences in the association between testosterone and violent behaviors. Trauma Mon. 2014;19(3):e18040. doi: 10.5812/traumamon.18040. [PubMed: 25337519]

25. Schmeelk-Cone KH, Zimmerman MA, Abelson JL. The buffering effects of active coping on the relationship between SES and cortisol among African American young adults. Behav Med. 2003;29(2):85-94. doi: 10.1080/08964280309596061. [PubMed: 15147107]

26. Derogatis LR, Melisaratos N. The Brief Symptom Inventory: an introductory report. Psychol Med. 1983;13(3):595-605. [PubMed: 6622612]

27. Derogatis LR, Lipman RS, Covi L. SCL-90: an outpatient psychiatric rating scale--preliminary report. Psychopharmacol Bull. 1973;9(1):13-28. [PubMed: 4682398]

28. Connolly MB, Crits-Christoph P, Shelton RC, Hollon S, Kurtz J, Barber JP, et al. The reliability and validity of a measure of selfunderstanding of interpersonal patterns. J Counseling Psycho. 1999;46(4):472.

29. Nadendla LK, Meduri V, Paramkusam G, Pachava KR. Relationship of salivary cortisol and anxiety in recurrent aphthous stomatitis. Indian J Endocrinol Metab. 2015;19(1):56-9. doi: 10.4103/22308210.131768. [PubMed: 25593827]

30. Harris A, Endresen Reme S, Tangen T, Hansen AM, Helene Garde A, Eriksen HR. Diurnal cortisol rhythm: Associated with anxiety and depression, or just an indication of lack of energy? Psychiatry Res. 2015;228(2):209-15. doi: 10.1016/j.psychres.2015.04.006. [PubMed: 26001959]

31. Nadendla LK, Meduri V, Paramkusam G, Pachava KR. Evaluation of salivary cortisol and anxiety levels in myofascial pain dysfunction syndrome. Korean J Pain. 2014;27(1):30-4. doi: 10.3344| kjp.2014.27.1.30. [PubMed: 24478898]

32. Assari S, Caldwell $\mathrm{CH}$, Zimmerman MA. Low parental support in late adolescence predicts obesity in young adulthood; Gender differences in a 12-year cohort of African Americans. J Diabetes Metab Disord. 2015;14:47. doi: 10.1186/s40200-015-0176-8. [PubMed: 26029673]

33. Aiyer SM, Heinze JE, Miller AL, Stoddard SA, Zimmerman MA. Exposure to violence predicting cortisol response during adolescence and early adulthood: understanding moderating factors. J Youth Adolesc. 2014;43(7):1066-79. doi:10.1007/s10964-014-0097-8. [PubMed: 24458765]

34. Zimmerman MA, Ramirez-Valles J, Zapert KM, Maton KI. A longitudinal study of stress-buffering effects for urban African-American male adolescent problem behaviors and mental health. J Community Psychol. 2000;28:17-33. doi: 10.1002/(SICI)15206629(200001)28:1<17::AID-JCOP4>3.3.CO;2-9.

35. Zimmerman MA, Steinman KJ, Rowe KJ. Violence among urban African American adolescents: The protective effects of parental support. In: Arriaga XB, Oskamp S, editors. Addressing community problems: Psychological research and interventions. Thousand Oaks, CA: Sage Publications; 1998. pp. 78-103.

36. Kudielka BM, Buske-Kirschbaum A, Hellhammer DH, Kirschbaum C. HPA axis responses to laboratory psychosocial stress in healthy elderly adults, younger adults, and children: impact of age and gender. Psychoneuroendocrinology. 2004;29(1):83-98. [PubMed: 14575731]

37. Kirschbaum C, Wust S, Hellhammer D. Consistent sex differences in cortisol responses to psychological stress. Psychosom Med.
1992:54(6):648-57. [PubMed:1454958]

38. Stroud LR, Salovey P, Epel ES. Sex differences in stress responses: social rejection versus achievement stress. Biol Psychiatry. 2002;52(4):318-27. [PubMed:12208639]

39. Handa RJ, Burgess LH, Kerr JE, O'Keefe JA. Gonadal steroid hormone receptors and sex differences in the hypothalamo-pituitary-adrenal axis. Horm Behav. 1994;28(4):464-76. doi: 10.1006| hbeh.1994.1044. [PubMed:7729815]

40. Kudielka BM, Hellhammer J, Hellhammer DH, Wolf OT, Pirke KM, Varadi E, et al. Sex differences in endocrine and psychological responses to psychosocial stress in healthy elderly subjects and the impact of a 2-week dehydroepiandrosterone treatment.J Clin Endocrinol Metab. 1998;83(5):1756-61. doi: 10.1210/jcem.83.5.4758. [PubMed: 9589688]

41. Kirschbaum C, Klauer T, Filipp SH, Hellhammer DH. Sex-specific effects of social support on cortisol and subjective responses to acute psychological stress. Psychosom Med. 1995;57(1):23-31. [PubMed: 7732155]

42. Kajantie E, Phillips DI. The effects of sex and hormonal status on the physiological response to acute psychosocial stress. Psychoneuroendocrinology. 2006;31(2):151-78. doi: 10.1016/j. psyneuen.2005.07.002. [PubMed:16139959]

43. Kudielka BM, Kirschbaum C. Sex differences in HPA axis responses to stress: a review. Biol Psychol. 2005;69(1):113-32. doi:10.1016/j. biopsycho.2004.11.009. [PubMed:15740829]

44. Badrick E, Bobak M, Britton A, Kirschbaum C, Marmot M, Kumari $\mathrm{M}$. The relationship between alcohol consumption and cortisol secretion in an aging cohort. J Clin Endocrinol Metab. 2008;93(3):750-7. doi:10.1210/jc.2007-0737. [PubMed:18073316]

45. Rasmussen DD, Boldt BM, Bryant CA, Mitton DR, Larsen SA, Wilkinson CW. Chronic daily ethanol and withdrawal: 1. Longterm changes in the hypothalamo-pituitary-adrenal axis. Alcohol Clin Exp Res. 2000;24(12):1836-49. [PubMed: 11141043]

46. Ogilvie K, Lee S, Weiss B, Rivier C. Mechanisms mediating the influence of alcohol on the hypothalamic-pituitary-adrenal axis responses to immune and nonimmune signals. Alcohol Clin Exp Res. 1998;22(5 Suppl):243S-7S. [PubMed: 9727644]

47. Junghanns K, Backhaus J, Tietz U, Lange W, Bernzen J, Wetterling T, et al. Impaired serum cortisol stress response is a predictor of early relapse. Alcohol Alcohol. 2003;38(2):189-93. [PubMed: 12634269]

48. Costa A, Bono G, Martignoni E, Merlo P, Sances G, Nappi G. An assessment of hypothalamo-pituitary-adrenal axis functioning in non-depressed, early abstinent alcoholics. Psychoneuroendocrinology. 1996;21(3):263-75. [PubMed: 8817725]

49. Bernardy NC, King AC, Parsons OA, Lovallo WR. Altered cortisol response in sober alcoholics: an examination of contributing factors. Alcohol.1996;13(5):493-8. [PubMed: 8888947]

50. Groote Veldman R, Meinders AE. On the mechanism of alcoholinduced pseudo-Cushing's syndrome. Endocr Rev. 1996;17(3):2628. doi:10.1210/edrv-17-3-262. [PubMed: 8771359]

51. Thayer JF, Hall M, Sollers JJ, Fischer JE. Alcohol use, urinary cortisol, and heart rate variability in apparently healthy men: Evidence for impaired inhibitory control of the HPA axis in heavy drinkers. Int J Psychophysiol. 2006;59(3):244-50. doi: 10.1016/j. ijpsycho.2005.10.013. [PubMed: 16325293]

52. Gianoulakis C, Dai X, Brown T. Effect of chronic alcohol consumption on the activity of the hypothalamic-pituitary-adrenal axis and pituitary beta-endorphin as a function of alcohol intake, age, and gender. Alcohol Clin Exp Res. 2003;27(3):410-23. doi: 10.1097/01.ALC.0000056614.96137.B8. [PubMed:12658106]

53. Yehuda R. Current status of cortisol findings in post-traumatic stress disorder. Psychiatr Clin North Am. 2002;25(2):341-68. [PubMed: 12136504]

54. Klimes-Dougan B, Hastings PD, Granger DA, Usher BA, ZahnWaxler C. Adrenocortical activity in at-risk and normally developing adolescents: individual differences in salivary cortisol basal levels, diurnal variation, and responses to social challenges. Dev Psychopathol. 2001;13(3):695-719. [PubMed: 11523855]

55. Ockenfels MC, Porter L, Smyth J, Kirschbaum C, Hellhammer $\mathrm{DH}$, Stone AA. Effect of chronic stress associated with unemployment on salivary cortisol: overall cortisol levels, diurnal rhythm, 
and acute stress reactivity. Psychosom Med. 1995;57(5):460-7. [PubMed: 8552737]

56. McLaughlin KA, Hilt LM, Nolen-Hoeksema S. Racial/ethnic differences in internalizing and externalizing symptoms in adolescents. J Abnorm Child Psychol. 2007;35(5):801-16. doi: 10.1007| s10802-007-9128-1. [PubMed: 17508278]

57. Anderson ER, Mayes LC. Race/ethnicity and internalizing disorders in youth: a review. Clin Psychol Rev. 2010;30(3):338-48. doi: 10.1016/j.cpr.20 09.12.008. [PubMed: 20071063]

58. Jackson JS, Knight KM, Rafferty JA. Race and unhealthy behaviors: chronic stress, the HPA axis, and physical and mental health disparities over the life course. Am J Public Health. 2010;100(5):933-9. doi:10.2105/AJPH.2008.143446. [PubMed: 19846689]

59. Black PH. The inflammatory consequences of psychologic stress: relationship to insulin resistance, obesity, atherosclerosis and diabetes mellitus, type II. Med Hypotheses. 2006;67(4):879-91. doi: 10.1016/j.mehy.2006.04.008. [PubMed:16781084]

60. Hjemdahl P. Stress and the metabolic syndrome: an interesting but enigmatic association. Circulation. 2002;106(21):2634-6. [PubMed: 12438283]

61. Rosmond R. Stress induced disturbances of the HPA axis: a pathway to Type 2 diabetes? Med Sci Monit. 2003;9(2):Ra35-9. [PubMed: 12601304]

62. Walker BR. Glucocorticoids and cardiovascular disease. Eur J Endocrinol. 2007;157(5):545-59. doi: 10.1530/EJE-07-0455. [PubMed: 17984234]

63. Fathi M, Alavi SM, Joudi M, Joudi M, Mahdikhani H, Ferasatkish R, et al. Preoperative anxiety in candidates for heart surgery. Iran Psychiatry Behav Sci. 2014;8(2):90-6. [PubMed: 25053963]

64. Ahmadi J, Amiri A, Ghanizadeh A, Khademalhosseini M, Khademalhosseini Z, Gholami Z, et al. Prevalence of Addiction to the
Internet, Computer Games, DVD, and Video and Its Relationship to Anxiety and Depression in a Sample of Iranian High Schoo Students. Iran J Psychiatry Behav Sci. 2014;8(2):75-80. [PubMed: 25053960

65. Mottaghi M, Atarodi A, Rohani Z. The Relationship between Coaches' and Athletes' Competitive Anxiety,and their Performance. Iran J Psychiatry Behav Sci. 2013;7(2):68-76. [PubMed 24644512

66. Farzaneh N, Ghobakhlou M, Moghimi-Dehkordi B, Naderi N, Fadai F. Anxiety and depression in a sample of Iranian patients with irritable bowel syndrome. Iran J Psychiatry Behav Sci. 2013;7(1):306. [PubMed: 24644497]

67. Assari S. Additive Effects of Anxiety and Depression on Body Mass Index among Blacks: Role of Ethnicity and Gender. Int Cardiovasc Res J. 2014;8(2):44-51. [PubMed: 24936480]

68. Assari S, Lankarani MM, Lankarani RM. Ethnicity Modifies the Additive Effects of Anxiety and Drug Use Disorders on Suicida Ideation among Black Adults in the United States. Int J Prev Med. 2013;4(11):1251-7. [PubMed:24404358]

69. van der Kaay D, van den Akker E. Ultralow-dose Dexamethasone to Preserve Endogenous Cortisol Stress Response in Nonclassical Congenital Adrenal Hyperplasia: A New Promising Treatment. Int J Endocrinol Metab. 2014;12(3):e14657. doi: 10.5812/ijem.14657. [PubMed: 25237318]

70. Assari S. Separate and Combined Effects of Anxiety, Depression and Problem Drinking on Subjective Health among Black, Hispanic and Non-Hispanic White Men. Int J Prev Med. 2014;5(3):26979. [PubMed: 24829710]

71. Modabbernia A, Poustchi H, Malekzadeh R. Neuropsychiatric and psychosocial issues of patients with hepatitis $\mathrm{C}$ infection: a selective literature review. Hepat Mon. 2013;13(1):e8340. doi: 10.5812/hepatmon.8340. [PubMed: 23550100] 